\title{
CrystEngComm
}

Check for updates

Cite this: CrystEngComm, 2020, 22, 8110

Received 10th September 2020

Accepted 15th October 2020

DOI: 10.1039/d0ce01320j

rsc.li/crystengcomm

\section{A novel one-pot strategy to rapidly synthesize bright red emitting upconversion nanocrystals with core-shell-shell structure $\uparrow$}

\author{
Zhiyuan Cheng, (D) ${ }^{a}$ Hao Lin, ${ }^{b}$ Tong Liu, ${ }^{a}$ Yongjin Li, (D) ${ }^{a}$ \\ Shenghong Yang ${ }^{a}$ and Yueli Zhang*a
}

\begin{abstract}
$\beta-\mathrm{NaErF}_{4}: 0.005 \mathrm{Tm}$ upconversion nanocrystals (UCNCs) with core-shell structure are quite popular due to efficient red upconversion luminescence. However, the traditional seed-mediated growth method is not continuous and quite time consuming, while the successive layer-by-layer strategy is unfriendly because of the usage of toxic sodium trifluoroacetate (Na-TFA). In this work, we utilized a novel one-pot strategy to synthesize $\beta-\mathrm{NaErF}_{4}: 0.005 \mathrm{Tm}$ with core-shell-shell structure. The morphology of the core could be significantly regulated. $\mathrm{NaYbF}_{4}$ and $\mathrm{NaYF}_{4}$ shells could be epitaxially grown on the core by simply adding fresh raw materials and heating to $300^{\circ} \mathrm{C}$, successively. Thanks to the suppression of surface quenching and energy back transfer from $\mathrm{Yb}^{3+}$ to $\mathrm{Er}^{3+}$, the population density of excited states of $\mathrm{Er}^{3+}\left({ }^{4} \mathrm{I}_{13 / 2},{ }^{4} \mathrm{I}_{11 / 2}\right.$ and $\left.{ }^{4} l_{9 / 2}\right)$ was much improved, resulting in the tremendously enhanced upconversion intensity of $\beta-\mathrm{NaErF}_{4}: 0.005 \mathrm{Tm} \mathrm{NaYbF} 4 \mathrm{NNaYF}_{4}$. This one-pot protocol could supply core-shell-shell red UCNCs with regular morphology, enhanced intensity and long-lasting decay lifetime, offering promising opportunities for applications such as bioprobing, anti-counterfeiting, photodynamic therapy, etc.
\end{abstract}

\section{Introduction}

Upconversion nanoparticles (UCNCs) activated by rare earth (RE) ions have been explored widely thanks to their unique properties such as large anti-Stokes shift, line emission, low toxicity, real intermediate level, and long lasting lifetime, and promising applications like sensing, detecting, bioimaging, photodynamic therapy, anti-counterfeiting, magnetic resonance imaging (MRI), ${ }^{1-14}$ etc.

Among all the UCNCs, $\beta-\mathrm{NaErF}_{4}$ is a promising candidate because it can be pumped using an 808/980/1532 nm laser and can emit red and green photons. ${ }^{15}$ However, its potential was limited by its poor efficiency. In 2017, $\mathrm{Liu}^{16}$ found out that slightly doped $\mathrm{Tm}^{3+}$ ions could act as energy trapping centers and significantly enhanced the upconversion luminescence (UCL). Thereafter, $\beta-\mathrm{NaErF}_{4}: 0.005 \mathrm{Tm}$ became well-known red emitting UCNCs, many researches followed up and now it is clear that $\beta-\mathrm{NaErF}_{4}: 0.005 \mathrm{Tm}$ has great potential for versatile applications. For example, $\mathrm{Mei}^{17}$

\footnotetext{
${ }^{a}$ State Key Laboratory of Optoelectronic Materials and Technologies, School of Materials Science and Engineering, Sun Yat-Sen University, Guangzhou, 510275, China.E-mail: stszyl@mail.sysu.edu.cn

${ }^{b}$ School of Physics and Materials Science, Guangzhou University/The Research Center for Advanced Information Materials, Huangpu Research \& Graduate School of Guangzhou University, Guangzhou 510006, China

$\dagger$ Electronic supplementary information (ESI) available. See DOI: 10.1039/ doce01320j
}

utilized $\beta-\mathrm{NaErF}_{4}: \mathrm{Tm}, \mathrm{Yb}$ as core and realized dumbbell shaped core-shell UCNCs with switchable upconversion under different excitation wavelengths; these UCNCs were then used for programmable activation of two ion channels, VChR1 and Jaws, for the purpose of membrane polarization. $\mathrm{Li}^{18} \quad$ conjugated $\beta-\mathrm{NaErF}_{4} @ \mathrm{NaLuF}_{4}$ with commercial photosensitizer Ce6 and applied the nanophotosensitizers for photodynamic therapy and multimode imaging. Wang ${ }^{19}$ reported that the $1525 \mathrm{~nm}$ emission of $\beta-\mathrm{NaErF}_{4} @ \mathrm{NaLuF}_{4}$ could be much enhanced by doping $20 \% \mathrm{Yb}^{3+}$ in the core. After coating with PAA, the UCNCs were used for short wave infrared imaging of cells and tissues and brain vasculature.

Despite so many works on $\beta-\mathrm{NaErF}_{4}: 0.005 \mathrm{Tm}$, the coreshell UCNCs were usually synthesized by only two traditional strategies: the seed-mediated growth method and successive layer-by-layer strategy. The seed-mediated growth method ${ }^{20-22}$ required no toxic substances (e.g. Na-TFA), but wasted plenty of time on repetitive washing, centrifuging and degassing because the synthesis of the core and shell is not continuous. The successive layer-by-layer strategy ${ }^{23-25}$ realized continuously synthesis of the shell but was not user-friendly because toxic Na-TFA must be used as shell precursor. Few studies concentrated on improving methods for rapid onepot synthesis. Chen $^{26}$ proposed a facile time-saving and effective solid-liquid-thermal-decomposition (SLTD) method to form $\beta-\mathrm{NaReF}_{4}(\mathrm{Re}=\mathrm{Sm}, \mathrm{Eu}, \mathrm{Gd}, \mathrm{Tb}, \mathrm{Y})$ nanocrystals. It was significant to realize the synthesis of $\beta-\mathrm{NaErF}_{4}: 0.005 \mathrm{Tm}$ 
by this fast SLTD method because of the unique excellent upconversion properties of $\beta-\mathrm{NaErF}_{4}: 0.005 \mathrm{Tm}$.

In this work, we developed this SLTD method and synthesized $\beta-\mathrm{NaErF}_{4}: 0.005 \mathrm{Tm}$ successfully. The influence of different experimental conditions on the morphology of the core was studied. $\beta-\mathrm{NaErF}_{4}: 0.005 \mathrm{Tm} @ \mathrm{NaYbF}_{4}, \beta-\mathrm{NaErF}_{4}: 0.005 \mathrm{Tm} @ \mathrm{NaYF}_{4}$ and $\quad \beta-\mathrm{NaErF}_{4}: 0.005 \mathrm{Tm} @ \mathrm{NaYbF}_{4} @ \mathrm{NaYF}_{4}$ with core-shell structure were also synthesized in one pot. The core-shell structure of $\beta-\mathrm{NaErF}_{4}: 0.005 \mathrm{Tm} @ \mathrm{NaYbF}_{4} @ \mathrm{NaYF}_{4}$ was proved by TEM images. The UCL intensity was tremendously enhanced and the upconversion enhancement mechanism was proposed.

\section{Experimental}

\subsection{Chemicals}

$\mathrm{RECl}_{3} \cdot 6 \mathrm{H}_{2} \mathrm{O}(\mathrm{RE}=\mathrm{Y}, \mathrm{Tm}, \mathrm{Yb})(99.99 \%), \mathrm{ErCl} \cdot 6 \mathrm{H}_{2} \mathrm{O}(99.5 \%)$, sodium acetate (NaAc) (A.R. 98\%), oleic acid (OA) (A.R. 85\%), 1-octadecene (1-ODE) (A.R. 90\%) and cyclohexane (99.5\%) were purchased from Aladdin. $\mathrm{NaHF}_{2}$ (A.R. 98\%) was purchased from Macklin. All materials were used without further purification.

\subsection{Synthesis of shell precursors $\mathrm{Yb}-\mathrm{OA}$ and $\mathrm{Y}-\mathrm{OA}$}

Before synthesizing UCNCs, the shell precursors Yb-OA and Y-OA were synthesized. In a typical experiment, $10 \mathrm{mmol}$ $\mathrm{RECl}_{3} \cdot 6 \mathrm{H}_{2} \mathrm{O}(\mathrm{RE}=\mathrm{Y}, \mathrm{Yb})$ was mixed with $40 \mathrm{~mL} \mathrm{OA}$ and 60 $\mathrm{mL}$ 1-ODE in a $250 \mathrm{~mL}$ three-neck round-bottom flask. After degassing for $10 \mathrm{~min}$ to remove oxygen, the mixture was heated to $160{ }^{\circ} \mathrm{C}$ under $\mathrm{N}_{2}$ flow with constant stirring to completely dissolve $\mathrm{RECl}_{3} \cdot 6 \mathrm{H}_{2} \mathrm{O}$, then cooled down to room temperature (RT) naturally. The obtained RE-OA solution was then stored in a $100 \mathrm{ml}$ bottle.

\subsection{Synthesis of $\alpha-\mathrm{NaErF}_{4}: 0.005 T m$ UCNCs}

The synthesis of $\alpha-\mathrm{NaErF}_{4}: 0.005 \mathrm{Tm}$ UCNCs named A0 could be described as follows: a stoichiometric amount of $\mathrm{RECl}_{3} \cdot 6 \mathrm{H}_{2} \mathrm{O}, 10 \mathrm{ml} \mathrm{OA}$ and $15 \mathrm{ml}$ 1-ODE was added into a $100 \mathrm{ml}$ three-neck round-bottom flask successively. After degassing for $10 \mathrm{~min}$ to remove oxygen, the resulting mixture was heated to $160{ }^{\circ} \mathrm{C}$ under $\mathrm{N}_{2}$ flow with constant stirring for $30 \mathrm{~min}$, then cooled down to RT. Thereafter, a stoichiometric amount of $\mathrm{NaHF}_{2}$ and $\mathrm{NaAc}$ was added, and the solution was heated and kept at $250{ }^{\circ} \mathrm{C}$ for $30 \mathrm{~min}$, then cooled down to RT. All of the obtained solutions were transferred into two centrifuge tubes and precipitated by the addition of ethanol. The precipitate was collected after centrifugation and washed with cyclohexane and ethanol 3 times, and re-dispersed in cyclohexane for further characterization.

\subsection{Synthesis of hexagonal core-only UCNCs}

All core-only UCNCs could be synthesized by similar procedures. As an example, sample B3 could be obtained by the following process: $1.5 \mathrm{mmol} \mathrm{RECl}_{3} \cdot 6 \mathrm{H}_{2} \mathrm{O}, 10 \mathrm{ml} \mathrm{OA}$ and $15 \mathrm{ml}$ 1-ODE were added into a $100 \mathrm{ml}$ three-neck roundbottom flask successively. After degassing for $10 \mathrm{~min}$ to remove oxygen, the resulting mixture was heated to $160{ }^{\circ} \mathrm{C}$ under $\mathrm{N}_{2}$ flow with constant stirring for $30 \mathrm{~min}$, then cooled down to RT. Thereafter, a stoichiometric amount of $\mathrm{NaHF}_{2}$ and $\mathrm{NaAc}$ was added, and the solution was heated and kept at $250{ }^{\circ} \mathrm{C}$ for $30 \mathrm{~min}$ and $300{ }^{\circ} \mathrm{C}$ for 90 min under $\mathrm{N}_{2}$ flow successively, then cooled down to RT. $10 \mathrm{ml}$ of the obtained solution was transferred into two centrifuge tubes and precipitated by the addition of ethanol. The precipitate was collected after centrifugation and washed with cyclohexane and ethanol 3 times, and re-dispersed in cyclohexane for further characterization.

\subsection{Synthesis of hexagonal core-shell UCNCs}

All core-shell UCNCs could be synthesized by similar procedures. As an example, $\beta-\mathrm{NaErF}_{4}$ :0.005Tm@NaYbF${ }_{4} @ \mathrm{NaYF}_{4}$ CSS (core-shell-shell) UCNCs were synthesized by a modified process. $\beta-\mathrm{NaErF}_{4}: 0.005 \mathrm{Tm}$ (core UCNCs) was first synthesized by the procedure mentioned above. Then, the middle absorption shell $\left(\mathrm{NaYbF}_{4}\right)$ was grown on the core. A stoichiometric amount of $\mathrm{Yb}-\mathrm{OA}$ and $\mathrm{NaHF}_{2}$ and $4 \mathrm{ml} \mathrm{OA}$ and $6 \mathrm{ml}$ 1-ODE were added successively. After degassing for $10 \mathrm{~min}$ to remove oxygen, the resulting mixture was heated and kept at $250{ }^{\circ} \mathrm{C}$ for $30 \mathrm{~min}$ and $300{ }^{\circ} \mathrm{C}$ for $90 \mathrm{~min}$ under $\mathrm{N}_{2}$ flow successively, then cooled down to RT. $10 \mathrm{ml}$ of the obtained solution was transferred into two centrifuge tubes and precipitated by the addition of ethanol. The precipitate was collected after centrifugation and washed with cyclohexane and ethanol 3 times, and re-dispersed in cyclohexane for further characterization. The outer inert shell $\left(\mathrm{NaYF}_{4}\right)$ was grown last. A stoichiometric amount of $\mathrm{Y}-\mathrm{OA}$ and $\mathrm{NaHF}_{2}$ and $4 \mathrm{ml} \mathrm{OA}$ and $6 \mathrm{ml}$ 1-ODE was added successively. After degassing for $10 \mathrm{~min}$ to remove oxygen, the resulting mixture was heated and kept at $250{ }^{\circ} \mathrm{C}$ for $30 \mathrm{~min}$ and $300{ }^{\circ} \mathrm{C}$ for $90 \mathrm{~min}$ under $\mathrm{N}_{2}$ flow successively, then cooled down to RT. All of the obtained solution was transferred into two centrifuge tubes and precipitated by the addition of ethanol. The precipitate was collected after centrifugation and washed with cyclohexane and ethanol 3 times, and re-dispersed in cyclohexane for further characterization. $\beta-\mathrm{NaErF}_{4}: 0.005 \mathrm{Tm} @ \mathrm{NaYbF}_{4}$ and $\beta-\mathrm{NaErF}_{4}: 0.005 \mathrm{Tm} @ \mathrm{NaYF}_{4}$ were synthesized by similar procedures and named CAS (core-absorption shell) and CIS (core-inert shell) UCNCs, respectively.

\subsection{Characterization}

Powder X-ray diffraction (XRD) patterns of all the samples were recorded using a Rigaku X-ray diffractometer (Smartlab, $\mathrm{Cu} \mathrm{K} \alpha$ radiation). TEM images were taken using an FEI transmission electron microscope (TEM, Tecnai G2 Spirit, $120 \mathrm{keV}$ ). High-angle annular dark field (HAADF) images and elemental linescans were obtained using an FEI TEM (FEI Tecnai G2 F30, $300 \mathrm{keV}$ ). Luminescence spectra and lifetime decay curves were measured using an Edinburgh Instruments setup (FLS 980) with $980 \mathrm{~nm}$ and $1532 \mathrm{~nm}$ diode lasers. 


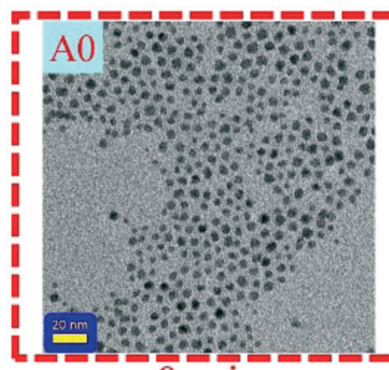

$0 \mathrm{~min}$

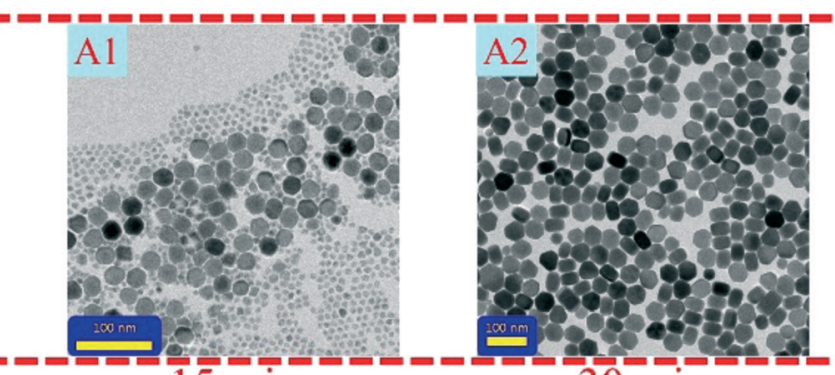

$30 \mathrm{~min}$

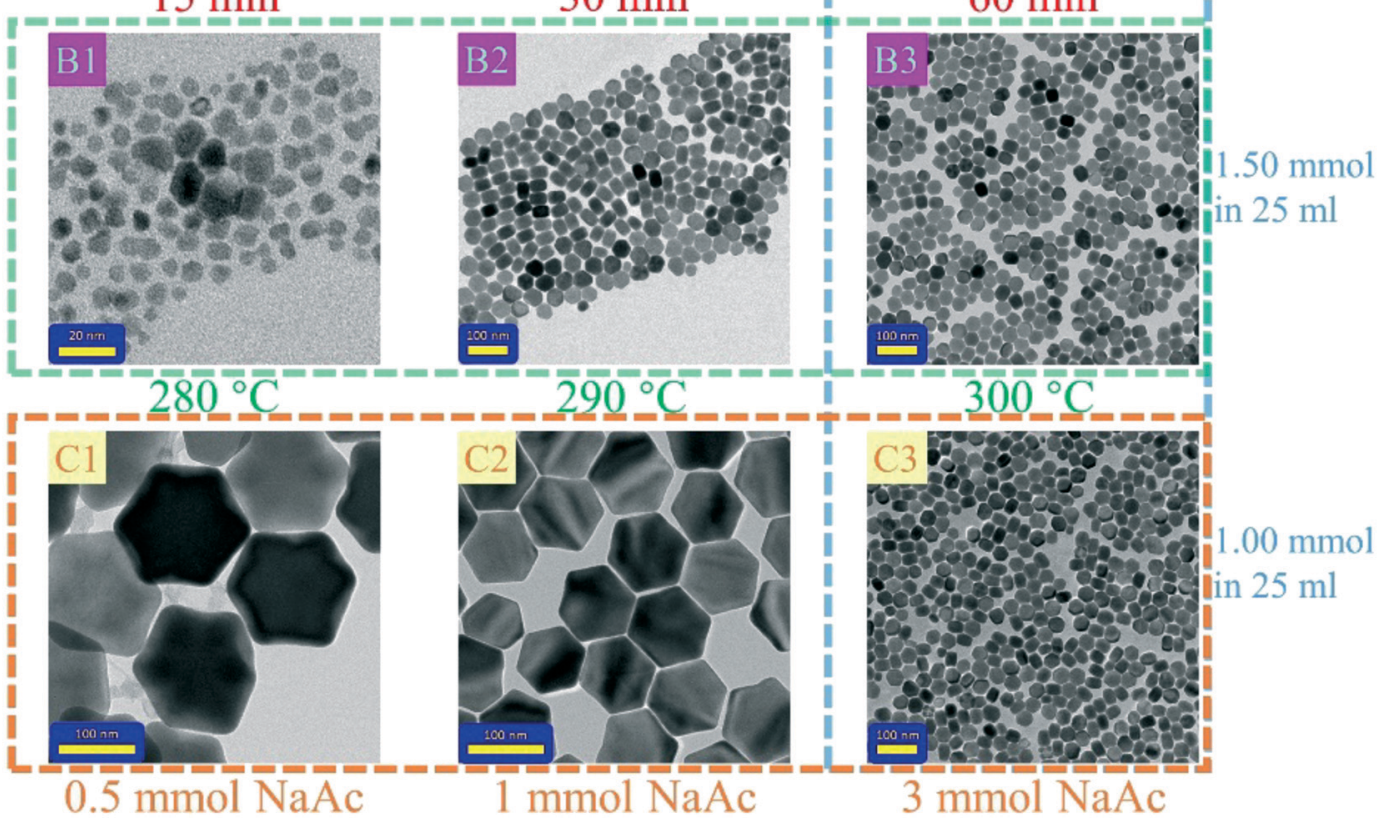

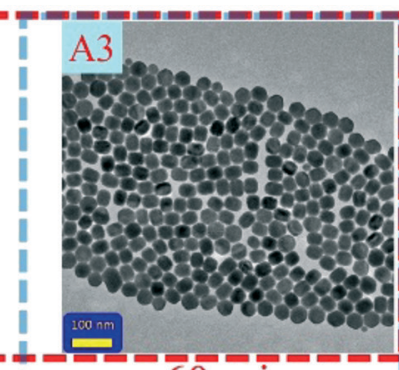

$60 \mathrm{~min}$

$.25 \mathrm{mmol}$ $25 \mathrm{ml}$

Fig. 1 TEM images of the UCNCs prepared under different experimental conditions. The variables of A0-A3, B1-B3, C1-C3 and A3-C3 were the synthesis duration, synthesis temperature, addition of $\mathrm{NaAc}$ and the molar weight of $\mathrm{RE}-\mathrm{OA}$ and $\mathrm{NaHF}_{2}$, respectively. The scale bars of $\mathrm{AO}$ and $\mathrm{B} 1$ were $20 \mathrm{~nm}$ and the others were $100 \mathrm{~nm}$.

\section{Results and discussion}

\subsection{Structure and morphology}

To obtain core-only $\beta-\mathrm{NaErF}_{4}: 0.005 \mathrm{Tm}$ with uniform morphology, multiple experimental conditions were optimized and their influence on the crystal structure and morphology was investigated thoroughly. The variation of morphology with synthesis duration is shown in Fig. 1A0-A3. Sample A0, heated to $250{ }^{\circ} \mathrm{C}$ for $30 \mathrm{~min}$, only contained small irregular nanoparticles, in which the phase was confirmed to be cubic ( $\alpha$-phase) by XRD as shown in Fig. 2 . Sample A1, kept at $300{ }^{\circ} \mathrm{C}$ for $15 \mathrm{~min}$, consisted of both hexagonal nanosheets with a size of about $20 \mathrm{~nm}$ and irregular nanoparticles. Meanwhile, the synthesis duration was extended to $30 \mathrm{~min}$, sample A2 only contained hexagonal nanosheets with a heterogeneous size. For sample A3 heated for $60 \mathrm{~min}$, only hexagonal nanosheets with a better size distribution were observed. Hence, the nanocrystal growth mechanism could be inferred as the Ostwald ripening process: the $\alpha$-phase was stable at a lower temperature $\left(250^{\circ} \mathrm{C}\right)$, but when the synthesis temperature was raised up to $300{ }^{\circ} \mathrm{C}$, the $\alpha$-phase became unstable, favoring the transition from $\alpha$ to $\beta$-phase, and the crystal seeds of the $\beta$-phase formed. As a consequence, the seeds of the $\beta$-phase grew into nanosheets at the cost of $\alpha$-phase irregular nanoparticles.

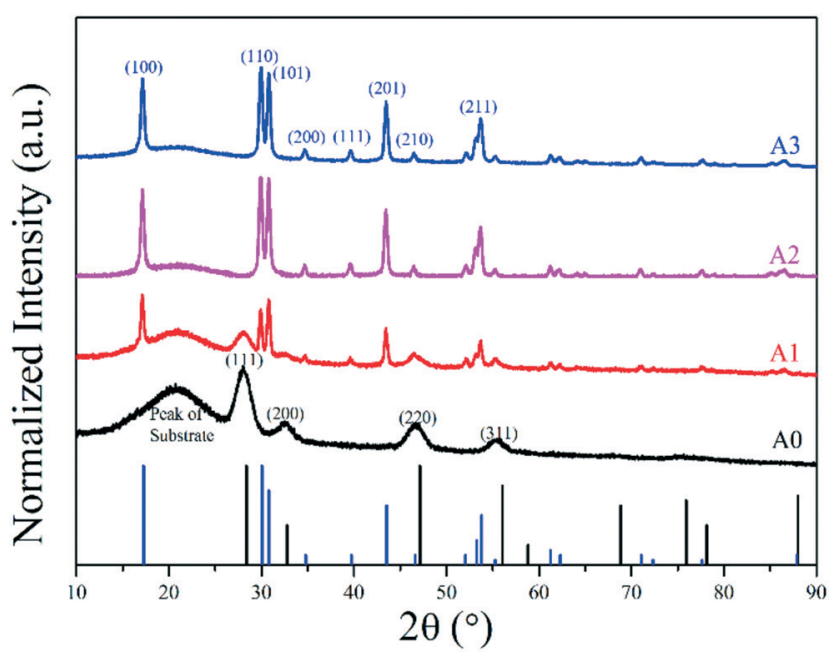

Fig. 2 XRD patterns of samples $A 0-A 3$, and the reaction duration at $300{ }^{\circ} \mathrm{C}$ of which was $0,15,30$, and $60 \mathrm{~min}$, respectively. The black vertical line was the standard XRD pattern of the $\alpha$ phase (PDF no. 270688) and the blue one was that of the $\beta$ phase (PDF no. 27-0689). 
The phase transition temperature was also confirmed. As shown in Fig. 1B1-B3 and S1, $\dagger$ while the synthesis duration was fixed at $60 \mathrm{~min}$, the temperature was varied from 280 to $300{ }^{\circ} \mathrm{C}$. The samples synthesized at 290 and $300{ }^{\circ} \mathrm{C}$ were pure hexagonal phases, while at $280{ }^{\circ} \mathrm{C}$, they were mostly cubic phases, suggesting that $290{ }^{\circ} \mathrm{C}$ is the lowest temperature to complete the transition from the cubic phase to the hexagonal phase.

It has been proposed that the $\mathrm{Na} / \mathrm{RE}$ ratio could influence the size of the final products. As the $\mathrm{Na} / \mathrm{RE}$ ratio increased, the formation of $\beta$-phase seeds was favored, leading to the reduction of the size of the final products. ${ }^{26}$ In our case, as shown in Fig. $1 \mathrm{C} 1-\mathrm{C} 3$, when adding $0.5-3 \mathrm{mmol} \mathrm{NaAc}$ into the flask, the average size of the as-synthesized samples remarkably decreased from $\sim 150$ to $38.3 \mathrm{~nm}$, which was consistent with the above theory. However, the size distribution of sample A3 was still diverging, which was not friendly for the subsequent epitaxial growth of a homogeneous shell. Surprisingly, we found that raising the molar weight of RE-OA and $\mathrm{NaHF}_{2}$ could overcome this drawback. As shown in Fig. 1 and $\mathrm{S} 2, \dagger$ when the molar weight of RE-OA and $\mathrm{NaHF}_{2}$ increased from 1 and $2 \mathrm{mmol}$ to 1.5 and $3 \mathrm{mmol}$, respectively, the standard deviation significantly decreased from 6.44 (C3) to 3.75 (B3), suggesting that the distribution was significantly restrained. Besides, the average size slightly decreased from $38.3 \mathrm{~nm}$ (C3) to $35.0 \mathrm{~nm}$ (B3) too. Our results suggested that the molar weight of all the raw materials, including $\mathrm{NaAc}, \mathrm{NaHF}_{2}$ and $\mathrm{RE}-\mathrm{OA}$, was a non-negligible factor influencing the size distribution of the final core samples.

Core-only UCNCs, especially UCNCs with nanometer size, suffered severe surface quenching due to their big specific surface area. The most effective strategy to avoid the surface quenching phenomenon was the epitaxial growth of an inert shell to cut off the energy transfer (ET) from the active/ sensitive ions to the surface quenching centers. ${ }^{16}$ Further, coating an absorption layer was also beneficial for the upconversion luminescence (UCL) intensity by improving the absorption cross section; hence, it was really important to realize convenient, rapid, user-friendly and one-pot synthesis of UCNCs with core-shell structure. In our previous work, we proved that inserting $\mathrm{NaYbF}_{4}$ shell between $\beta-\mathrm{NaErF}_{4}: 0.005 \mathrm{Tm}$ and inert shell could obviously enhance the UCL intensity. For the purpose of intensity enhancement, we carried out the one-pot synthesis of $\beta-\mathrm{NaErF}_{4}: 0.005 \mathrm{Tm}$ (core), $\beta-\mathrm{NaErF}_{4}: 0.005 \mathrm{Tm} @ \mathrm{NaYF}_{4}$ (CIS), $\beta-\mathrm{NaErF}_{4}: 0.005 \mathrm{Tm} @ \mathrm{NaYbF}_{4}$ (CAS) and $\beta-\mathrm{NaErF}_{4}: 0.005 \mathrm{Tm} @ \mathrm{NaYbF}_{4} @ \mathrm{NaYF}_{4}$ (CSS) and their TEM images were shown in Fig. 3. The sample core and the cores of CIS, CAS and CSS were synthesized by the same method; the molar weights of the shells of CIS and CAS and the middle shell of CSS were consistent with half of the molar weight of outer shell of CSS. It could be seen that as the shell

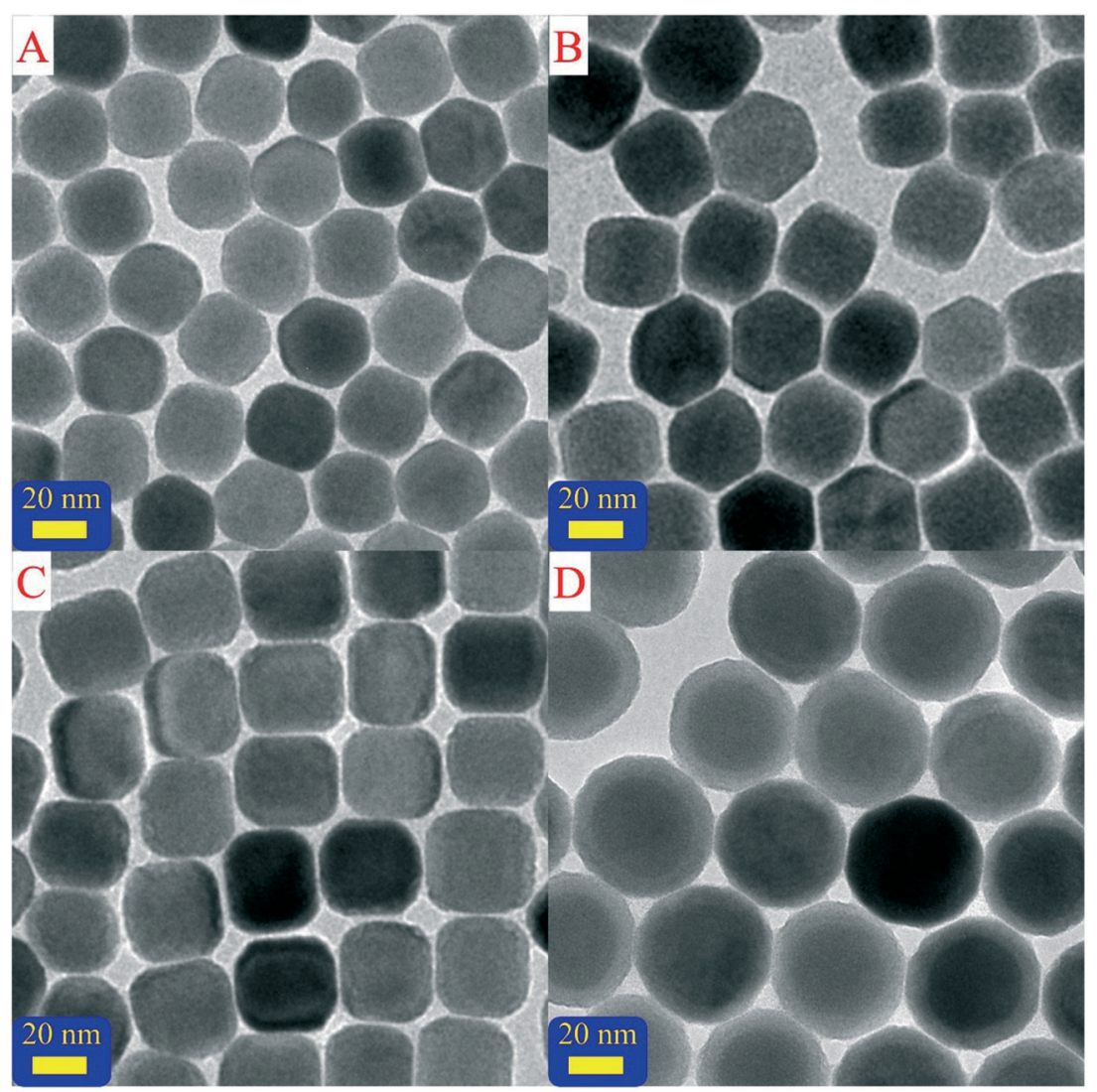

Fig. 3 TEM images of $\beta-\mathrm{NaErF}_{4}: 0.005 \mathrm{Tm}$ (core), $\beta-\mathrm{NaErF}_{4}: 0.005 \mathrm{TmaNaYF}_{4}$ (CIS)

$\beta-\mathrm{NaErF}_{4}: 0.005 \mathrm{TmaNaYbF}_{4} \quad$ (CAS)

(CAS) and $\beta-\mathrm{NaErF}_{4}: 0.005 \mathrm{TmaNaYbF}_{4} \mathrm{aNaYF}_{4}$ (CSS) labeled as A-D, respectively. The scale bars were $20 \mathrm{~nm}$. 
was coated on the core, the samples were clearly enlarged. As shown in Table $\mathrm{S} 1, \uparrow$ the average sizes of the core, CIS, CAS and CSS were 31.0, 35.8, 35.5 and $48.6 \mathrm{~nm}$, respectively. The outer $\mathrm{NaYF}_{4}$ shell could be easily distinguished from the core and middle shell by its lower grey value because the ability of $\mathrm{Y}^{3+}$ to scatter electrons is weaker than that of $\mathrm{Er}^{3+}$ and $\mathrm{Yb}^{3+}$. Additional evidence for the core-shell-shell structure was the elemental linescans and elemental mapping of sample CSS, as shown in Fig. S3 and S4. $\uparrow$ The signals of $\mathrm{Er}^{3+}$ and $\mathrm{Yb}^{3+}$ ions were majorly distributed in the core and core-shell areas, respectively; meanwhile, the signals of $\mathrm{Y}^{3+}$ ions were majorly distributed in the outer shell area. These results indicated that all the $\mathrm{RE}^{3+}$ ions were well confined in the pre-designed layers.

\subsection{Upconversion luminescence (UCL) and mechanisms}

The upconversion luminescence (UCL) of $\beta-\mathrm{NaErF}_{4}: 0.005 \mathrm{Tm}$ is really important for its applications. Thanks to the abundant substates of $\mathrm{Er}^{3+}$ ions, $\beta-\mathrm{NaErF}_{4}: 0.005 \mathrm{Tm}$ could be efficiently excited with both 980 and $1532 \mathrm{~nm}$ lasers, corresponding to the ${ }^{4} \mathrm{I}_{11 / 2}$ and ${ }^{4} \mathrm{I}_{13 / 2}$ states with an ideal absorption cross section, respectively. Fig. 4 showed the UCL spectra and decay lifetime curves of the samples core, CAS, CIS and CSS excited with 980 and $1532 \mathrm{~nm}$ lasers, respectively. In Fig. 4a and c, it could be seen that the spectra were mainly distributed in the red region peaking at $654 \mathrm{~nm}$ corresponding to the electron transition ${ }^{4} \mathrm{~F}_{9 / 2} \rightarrow{ }^{4} \mathrm{I}_{15 / 2}$. The weaker emissions at the green region (520/ $\left.540 \mathrm{~nm},{ }^{2} \mathrm{H}_{11 / 2} /{ }^{4} \mathrm{~S}_{3 / 2} \rightarrow{ }^{4} \mathrm{I}_{15 / 2}\right)$ and the weakest emissions at the near infrared (NIR) region (808 nm, $\left.{ }^{4} \mathrm{I}_{9 / 2} \rightarrow{ }^{4} \mathrm{I}_{15 / 2}\right)$ were observed too. The red to green ratio $(\mathrm{R} / \mathrm{G})$ of CSS was about 24.6 and 9.18 under 980 and $1532 \mathrm{~nm}$ lasers, respectively. The UCL intensities of core, CAS and CIS were much weaker than that of CSS under both 980 and $1532 \mathrm{~nm}$ lasers as listed in Table S2.† Compared with $\beta-\mathrm{NaErF}_{4}: 0.005 \mathrm{Tm}$ (core), the intensity of CSS could be 291/17366 folds enhanced when pumped with either the 980 $\mathrm{nm}$ laser or the $1532 \mathrm{~nm}$ laser. The outer $\mathrm{NaYF}_{4}$ shell could suppress the surface quenching effect, i.e. the energy transfer
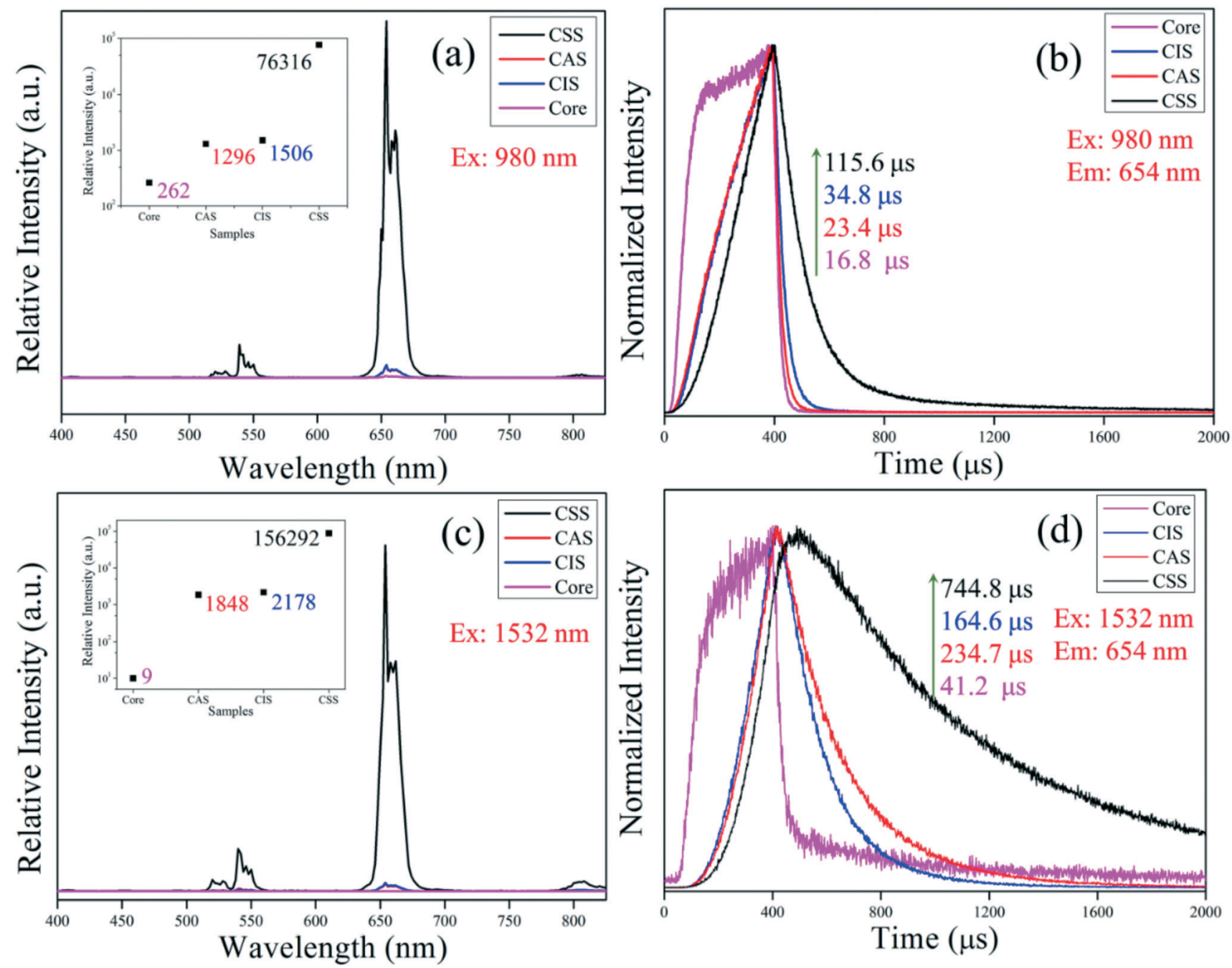

Fig. 4 The upconversion luminescence (UCL) spectra (a and c) and decay lifetime curves (b and d) of $\beta-\mathrm{NaErF}_{4}: 0.005 \mathrm{Tm}$ (core), $\beta-\mathrm{NaErF}_{4}: 0.005 \mathrm{TmaNaYbF}_{4}$ (CAS), $\beta-\mathrm{NaErF}_{4}: 0.005 \mathrm{Tm}_{\mathrm{aNaYF}}$ (CIS) and $\beta-\mathrm{NaErF}_{4}: 0.005 \mathrm{TmaNaYbF}_{4} \mathrm{aNaYF}_{4}$ (CSS). The laser power density was 10 $\mathrm{W} \mathrm{cm}{ }^{-2}$. 

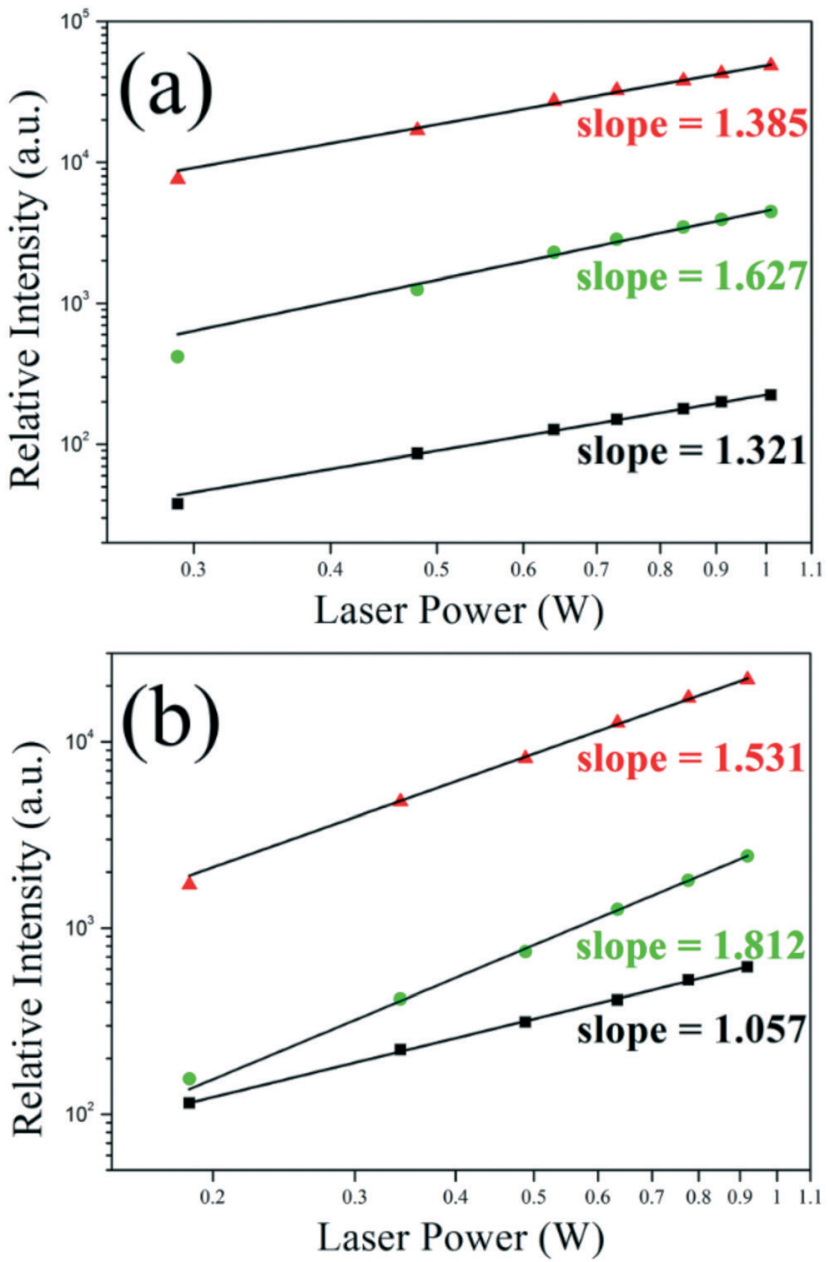

Fig. 5 The double logarithmic relationship of the NIR $(808 \mathrm{~nm})$, red $(654 \mathrm{~nm})$ and green $(540 \mathrm{~nm})$ UCL intensities versus the laser powers of the sample CSS pumped with $980 \mathrm{~nm}$ (a) and $1532 \mathrm{~nm}$ (b) lasers, respectively.

(ET) from active/sensitive ions to surface defects or ligands. When the inert shell stopped the leakage of energy, the population density of the excited states of the $\mathrm{Er}^{3+}$ ions $\left({ }^{4} \mathrm{I}_{13 / 2}\right.$, ${ }^{4} \mathrm{I}_{11 / 2},{ }^{4} \mathrm{I}_{9 / 2},{ }^{4} \mathrm{~F}_{9 / 2},{ }^{4} \mathrm{~S}_{3 / 2}$, and ${ }^{2} \mathrm{H}_{11 / 2}$ ) raised and the UCL intensity was largely increased. As shown in Fig. $4 \mathrm{~b}$ and d, the lifetimes of core, CAS, CIS and CSS were 16.8, 23.4, 34.8 and $115.6 \mu \mathrm{s}$, respectively, when excited with the $980 \mathrm{~nm}$ laser, and 42.1, 234.7, 164.6 and $744.8 \mu$ s, respectively, when excited with the $1532 \mathrm{~nm}$ laser. This was direct evidence for the shielding effects of outer $\mathrm{NaYF}_{4}$. When the ET from activators to surface quenching centers was cut off, the UCL efficiency increased and the lifetime was prolonged. What's more, the population density of the lower states of $\operatorname{Er}^{3+}\left({ }^{4} \mathrm{I}_{13 / 2},{ }^{4} \mathrm{I}_{11 / 2}\right.$ and $\left.{ }^{4} \mathrm{I}_{9 / 2}\right)$ would also be enlarged by the suppression of surface quenching. Influenced by the enlarged population density of the lower states, the decay lifetime of ${ }^{4} \mathrm{~F}_{9 / 2}$ (upper states) was prolonged too.

Fig. 5 and $55 \dagger$ displayed the double logarithmic relationship of the UCL intensity versus laser power and the upconversion luminescence spectra of the sample CSS, respectively. It could be seen that when pumped by the 980 $\mathrm{nm}$ laser, the slopes of the red, green and NIR peaks were $1.385,1.627$ and 1.321 , slightly deviated from the theoretical value $(n=2)$, suggesting that only the first excited state $\left({ }^{4} \mathrm{I}_{13 / 2}\right)$ was partly saturated. However, when pumped by the $1532 \mathrm{~nm}$ laser, the slope of the red, green and NIR peaks was only 1.531, 1.812 and 1.057, respectively. It was well-known that the UCL from $\operatorname{Er}^{3+} @{ }^{4} \mathrm{~F}_{9 / 2}$ or ${ }^{4} \mathrm{~S}_{3 / 2} /{ }^{2} \mathrm{H}_{11 / 2}$ was a threephoton process and the UCL from $\mathrm{Er}^{3+} @{ }^{4} \mathrm{I}_{9 / 2}$ was a twophoton process when pumped with the $1532 \mathrm{~nm}$ laser; hence, these experimental values greatly deviated from the theoretical value. The sound reason for this deviation was the complete saturation of ${ }^{4} \mathrm{I}_{13 / 2}$ and the partial saturation of ${ }^{4} \mathbf{I}_{11 / 2}$ and ${ }^{4} \mathbf{I}_{9 / 2}$ of $\mathrm{Er}^{3+} \cdot{ }^{27-29}$ This deduction could be supported by the lifetime curves. As indicated in Fig. 4d, when the 1532 $\mathrm{nm}$ laser shut down at $0.4 \mathrm{~ms}$, unlike other samples or pumped with the $980 \mathrm{~nm}$ laser, the emission intensity of CSS not only didn't decline immediately, but also increased to the max value of about $0.1 \mathrm{~ms}$ later. That was to say, after $0.4 \mathrm{~ms}$ excitation with the $1532 \mathrm{~nm}$ laser, the population density of

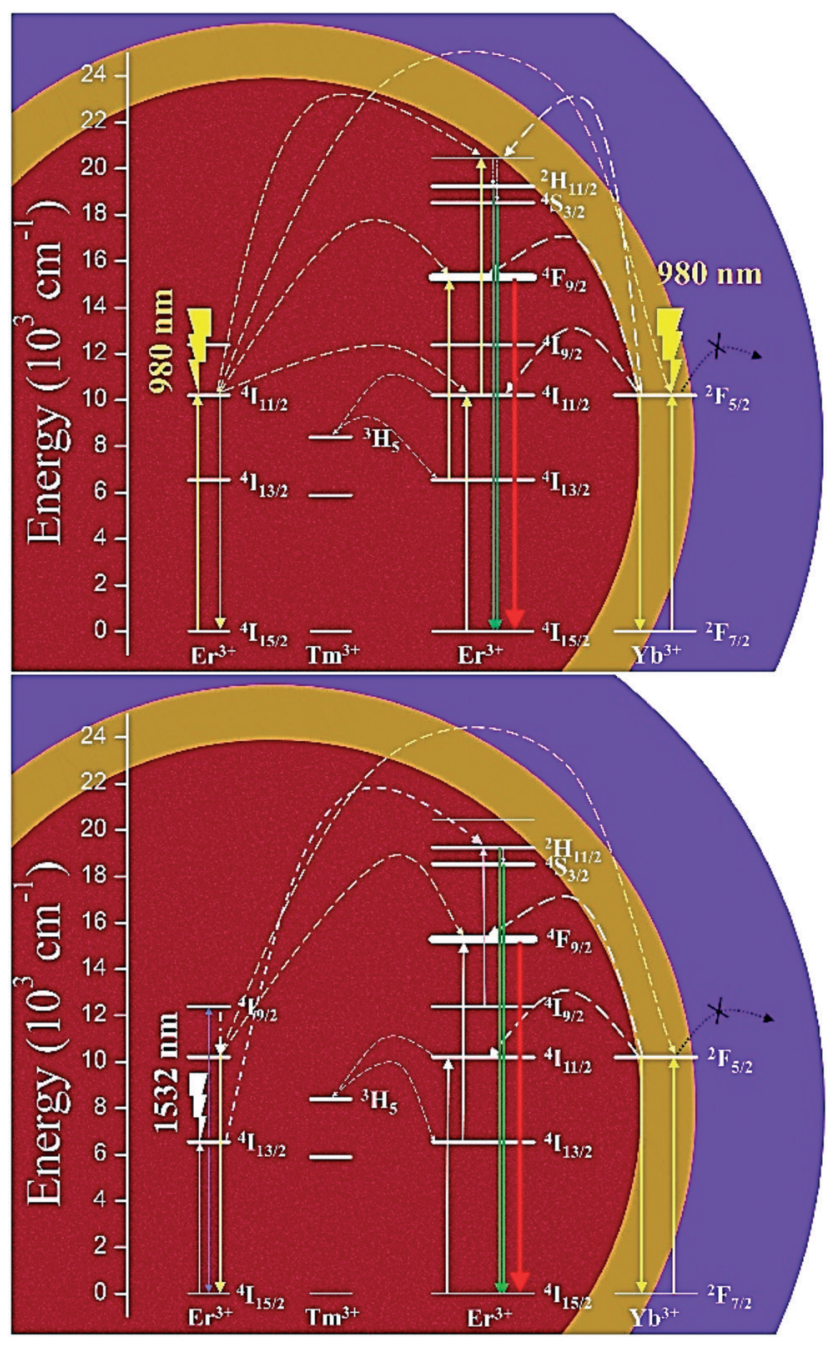

Fig. 6 The proposed energy transfer mechanisms of $\beta-\mathrm{NaErF}_{4}: 0.005 \mathrm{TmaNaYbF}_{4} \mathrm{aNaYF}_{4}$ CSS UCNCs excited with $980 \mathrm{~nm}$ laser (top) and $1532 \mathrm{~nm}$ lasers (bottom), respectively. 
${ }^{4} I_{13 / 2},{ }^{4} I_{11 / 2}$ and ${ }^{4} I_{9 / 2}$ was large enough to enhance the UCL intensity without continuous pumping for $\sim 0.1 \mathrm{~ms}$. Besides, the lifetime was longer when they were excited with the 1532 $\mathrm{nm}$ laser compared with the $980 \mathrm{~nm}$ laser, indicating that the population density of ${ }^{4} \mathrm{I}_{13 / 2},{ }^{4} \mathrm{I}_{11 / 2}$ and ${ }^{4} \mathrm{I}_{9 / 2}$ was larger when pumped with the $1532 \mathrm{~nm}$ laser. The lifetime decay curve of ${ }^{4} \mathbf{I}_{9 / 2}$ is also shown in Fig. S7. $\dagger$ As a comparison, the lifetime of ${ }^{4} \mathrm{I}_{9 / 2}$ pumped with the $1532 \mathrm{~nm}$ laser was slightly lower than that with the $980 \mathrm{~nm}$ laser, which should have originated from the more intense interaction ${ }^{4} \mathrm{I}_{9 / 2}+{ }^{4} \mathrm{I}_{13 / 2} \rightarrow$ ${ }^{2} \mathrm{H}_{11 / 2}+{ }^{4} \mathrm{I}_{15 / 2}$ because the population density of ${ }^{4} \mathrm{I}_{13 / 2}$ was higher when pumped with the $1532 \mathrm{~nm}$ laser, which was also consistent with our deduction.

The UCL mechanism is briefly summarized and shown in Fig. 6. Both red and green UCLwere a two-photon process when pumped with the $980 \mathrm{~nm}$ laser, and a three-photon process when pumped with the $1532 \mathrm{~nm}$ laser. The outer $\mathrm{NaYF}_{4}$ shell (purple area) cuts off the energy leakage and prevents the surface quenching effects. The $\mathrm{Yb}^{3+}$ ions in the middle $\mathrm{NaYbF}_{4}$ shell (yellow area) could be excited by directly absorbing $980 \mathrm{~nm}$ photons or accepting energy from $\mathrm{Er}^{3+}$ in the core; thereafter, $\mathrm{Yb}^{3+}:{ }^{2} \mathrm{~F}_{5 / 2}$ transferred energy back to $\mathrm{Er}^{3+}::_{13 / 2}^{4}$ or ${ }^{4} \mathrm{I}_{11 / 2}$, causing $\mathrm{Er}^{3+}::^{4} \mathrm{~F}_{9 / 2}$ or $\mathrm{Er}^{3+}:{ }^{4} \mathrm{~S}_{3 / 2} /{ }^{2} \mathrm{H}_{11 / 2}$ with high efficiency. The population densities of the lower excited states of $\mathrm{Er}^{3+}\left({ }^{4} \mathrm{I}_{13 / 2},{ }^{4} \mathrm{I}_{11 / 2}\right.$, and $\left.{ }^{4} \mathrm{I}_{9 / 2}\right)$ were largely boosted thanks to both the suppression of the surface quenching and energy back transfer from $\mathrm{Yb}^{3+}$ to $\mathrm{Er}^{3+}$, resulting in the tremendous enhancement of the UCL intensity.

\section{Conclusion}

In summary, a successive one-pot strategy to synthesize $\beta-\mathrm{NaErF}_{4}: 0.005 \mathrm{Tm}$ with core-multishell structure was presented. Different experimental conditions were varied to obtain core-only $\beta$ - $\mathrm{NaErF}_{4}: 0.005 \mathrm{Tm}$ with uniform morphology and suitable size for further shell growth. The nanocrystal growth process was confirmed to be Ostwald ripening. To coat outer shells, RE-OA precursors, $\mathrm{NaHF}_{2}$ powders and fresh OA/1-ODE were added into the reaction flask and heated at $300{ }^{\circ} \mathrm{C}$; no extra complex steps were needed. What's more, this method could be used to coat multiple shells successively. The middle $\mathrm{NaYbF}_{4}$ layer could transfer energy back to $\mathrm{Er}^{3+}$ in the core, and the $\mathrm{NaYF}_{4}$ layer cuts off the energy transfer from the sensitizer/activator to surface quenching centers. Thanks to these effects, the population density of the excited states of $\operatorname{Er}^{3+}\left({ }^{4} I_{13 / 2},{ }^{4} I_{11 / 2}\right.$, and $\left.{ }^{4} I_{9 / 2}\right)$ was partly or completely saturated, resulting in the tremendous enhancement of upconversion luminescence (UCL) intensity. This UCL mechanism was supported by both lifetime decay curves and double logarithmic relationship of the UCL intensity versus laser powers. These results suggested that our successive one-pot strategy was simple, controllable and time-saving to synthesize core-shell-shell $\beta$-NaErF 4 :0.005Tm@NaYbF $4 @ \mathrm{NaYF}_{4}$ with much enhanced red UCL, making it suitable for versatile applications such as bioprobing, anti-counterfeiting, and photodynamic therapy.

\section{Conflicts of interest}

There are no conflicts of interest to declare.

\section{Acknowledgements}

This work was supported by the National Natural Science Foundation of China (No. 61975245), the Science and Technology Planning Project of Guangdong Province (No. 2017A010103035), a start-up foundation from Guangzhou University under Grant No. 69-18ZX10334, and the Youth Innovative Talents Project in Colleges and Universities in Guangdong Province under Grant No. 2018KQNCX193.

\section{References}

1 Z. M. Zhang, S. Shikha, J. L. Liu, J. Zhang, Q. S. Mei and Y. Zhang, Anal. Chem., 2019, 91, 548-568.

2 X. H. Zhu, J. Zhang, J. L. Liu and Y. Zhang, Adv. Sci., 2019, 6(22), 1901358.

3 L. D. Sun, Y. F. Wang and C. H. Yan, Acc. Chem. Res., 2014, 47(4), 1001-1009.

4 S. L. Gai, C. X. Li, P. P. Yang and J. Lin, Chem. Rev., 2014, 114(4), 2343-2389.

5 Y. Y. Liu, X. F. Meng and W. B. Bu, Coord. Chem. Rev., 2019, 379, 82-98.

6 J. J. Zhou, J. L. Leaño Jr., Z. Y. Liu, D. Y. Jin, K.-L. Wong, R.-S. Liu and J.-C. G. Bünzli, Small, 2018, 14(40), 1801882.

7 H. H. Gorris and U. Resch-Genger, Anal. Bioanal. Chem., 2017, 409(25), 5875-5890.

8 J. Zhao, H. Q. Chu, Y. Zhao, Y. Lu and L. L. Li, J. Am. Chem. Soc., 2019, 141(17), 7056-7062.

9 M. Wang, J. Song, F. F. Zhou, A. R. Hoover, C. Murray, B. Q. Zhou, L. Wang, J. L. Qu and W. R. Chen, Adv. Sci., 2019, 6(10), 1802157.

10 H. Rabie, Y. X. Zhang, N. Pasquale, M. J. Lagos, P. E. Batson and K.-B. Lee, Adv. Mater., 2019, 31(14), 1806991.

11 Z. B. Luo, Q. G. Qi, L. J. Zhang, R. J. Zeng, L. S. Su and D. P. Tang, Anal. Chem., 2019, 91(6), 4149-4156.

12 Y. Q. Hu, Q. Y. Shao, X. Y. Deng, D. D. Song, S. Y. Han, Y. Dong and J. Q. Jiang, J. Mater. Chem. C, 2019, 7, 11770-11775.

13 Q. Chen, C. Wang, L. Cheng, W. W. He, Z. P. Cheng and Z. Liu, Biomaterials, 2014, 35(9), 2915-2923.

14 W. P. Fan, B. Shen, W. B. Bu, F. Chen, Q. J. He, K. L. Zhao, S. J. Zhang, L. P. Zhou, W. J. Peng, Q. F. Xiao, D. L. Ni, J. N. Liu and J. L. Shi, Biomaterials, 2014, 35(32), 8992-9002.

15 H. Lin, D. K. Xu, Z. Y. Cheng, Y. J. Li and Y. L. Zhang, Appl. Surf. Sci., 2020, 514, 146074.

16 Q. S. Chen, X. J. Xie, B. L. Huang, L. L. Liang, S. Y. Han, Z. G. Yi, Y. Wang, Y. Li, D. Y. Fan, L. Huang and X. G. Liu, Angew. Chem., Int. Ed., 2017, 56(26), 7605-7609.

17 Q. S. Mei, A. Bansal, M. K. G. Jayakumar, Z. M. Zhang, J. Zhang, H. Huang, D. J. Yu, C. J. A. Ramachandra, D. J. Hausenloy, T. W. Soong and Y. Zhang, Nat. Commun., 2019, 10, 4416.

18 Q. Q. Li, X. D. Li, L. Zhang, J. Zuo, Y. L. Zhang, X. M. Liu, L. P. Tu, B. Xue, Y. L. Chang and X. G. Kong, Nanoscale, 2018, 10, 12356-12363. 
19 X. Wang, A. Yakovliev, T. Y. Ohulchanskyy, L. N. Wu, S. J. Zeng, X. J. Han, J. L. Qu and G. Y. Chen, Adv. Opt. Mater., 2018, 6(20), 1800690.

20 Z. Q. Li and Y. Zhang, An efficient and user-friendly method for the synthesis of hexagonal-phase $\mathrm{NaYF}_{4}: \mathrm{Yb} / \mathrm{Er} / \mathrm{Tm}$ nanocrystals with controllable shape and upconversion fluorescence, Nanotechnology, 2008, 19(34), 345606.

21 H. S. Qian and Y. Zhang, Langmuir, 2008, 24(21), 12123-12125.

22 F. Wang, J. Wang and X. G. Liu, Angew. Chem., Int. Ed., 2010, 49(41), 7456-7460.

23 X. M. Li, D. K. Shen, J. P. Yang, C. Yao, R. C. Che, F. Zhang and D. Y. Zhao, Chem. Mater., 2013, 25(1), 106-112.

24 L. Lei, X. R. Dai, Y. Cheng, Y. S. Wang, Z. Xiao and S. Q. Xu, J. Mater. Chem. C, 2019, 7, 3342-3350.
25 H. Lakhotiya, A. Nazir, S. Roesgaard, E. Eriksen, J. Christiansen, M. Bondesgaard, F. C. J. M. van Veggel, B. B. Iversen, P. Balling and B. Julsgaard, ACS Appl. Mater. Interfaces, 2019, 11(1), 1209-1218.

26 W. W. You, D. T. Tu, W. Zheng, X. Y. Shang, X. R. Song, S. Y. Zhou, Y. Liu, R. F. Li and X. Y. Chen, Nanoscale, 2018, 10, 11477-11484.

27 C. Homann, L. Krukewitt, F. Frenzel, B. Grauel, U. ReschGenger and M. Haase, $\mathrm{NaYF}_{4}: \mathrm{Yb}, \mathrm{Er} / \mathrm{NaYF}_{4}$ core/shell nanocrystals with high upconversion luminescence quantum yield, Angew. Chem., Int. Ed., 2018, 57(28), 8765-8769.

28 U. Resch-Genger and H. H. Gorris, Anal. Bioanal. Chem., 2017, 409(25), 5855-5874.

29 C. Würth, M. Kaiser, S. Wilhelm, B. Grauel, T. Hirsch and U. Resch-Genger, Nanoscale, 2017, 9, 4283-4294. 